\title{
Obras públicas en Talavera de la Reina: los puentes medievales. Aproximación histórica y arqueológica
}

\author{
César PACHECo JimÉnez \\ UNED. Centro Asociado de Talavera de la Reina
}

\begin{abstract}
RESUMEN
Los puentes en la Edad Media constituían un elemento de vital importancia para las comunicaciones

terrestres. Su construcción y mantenimiento repercutían a menudo en el desarrollo de las tierras, ciudades $y$ aldeas que se beneficiaban de los mismos. Como obra pública entendemos que los puentes medievales de Talavera de la Reina no estuvieron a la altura de las necesidades que tenia esta villa y su tierra. En este artículo analizamos desde la perspectiva histórica y arqueológica tres ejemplos de puentes medievales y sus antecedentes, para aportar nuevos datos al estudio de las infraestructuras viarias de la zona toledana y, por tanto, de la Castilla bajomedieval.
\end{abstract}

\begin{abstract}
In the Midle Age the bridges were an element of vital importance for the communications by land. Their construction and maintenance had often effects on lands, cities and villages development and that was of great benefit to places. As pyblic works we know medieval bridges in Talavera de la Reina were not enough to the necessity of the city and its land. In this article we analyse from the historic and archaeologist view three exemples of medieval bridges and previous buildings in order to dive information to the communications network research in the Toledo area and therefore in medieval Castilla.
\end{abstract}




\section{INTRODUCCIÓN}

La vega del Tajo donde se asienta Talavera de la Reina es sin duda un área de especial interés desde el punto de vista histórico; su fertilidad ha originado desde la Prehistoria un continuo aprovechamiento y asentamiento por parte de diversas culturas. El cauce del río Tajo en esta zona se alimenta de varios arroyos y de un afluente fundamental que le proporciona un considerable caudal: el Alberche. Los diferentes arroyos que riegan esta vega se disponen en la vertiente norte del valle surcándola de norte a sur generalmente (Portiña, Papacochinos, Bárrago, Albaladiel, etc.), y en la meridional, donde los materiales terciarios de arcosas y arcillas se ven drenados por el río Sangrera, otro de las grandes aportes hídricos al Tajo, y arroyos como Valgrande, Aceitunilla o Chascoso.

En la vertiente norte del valle del Tajo el relieve característico es el de las terrazas aluviales cuaternarias sobre materiales graníticos paleozoi$\cos ^{1}$, dispuestas de forma escalonada dieron asiento a los primeros pobladores prehistóricos del lugar; en varios puentos de las mismas se ha localizado industria del paleolítico inferior ${ }^{2}$.

La dispersión de tantos cursos de agua convierten a Talavera en un lugar que, a pesar de su clima mediterráneo, con épocas de estiajes, la presencia del elemento acuífero es muy importante, hasta tal punto de que históricamente la vinculación a la aguas es un factor de interpretación de ciertos comportamientos de la mentalidad colectiva ${ }^{3}$. El riego, la huerta, el canal, la noria, el pozo, la fuente, etc. son expresiones culturales de una determinada relación entre la comunidad que ejerce una acción antrópica y el medio en el que se desarrolla.

1 JIMÉNEZ, J. Carlos: “Geografía física en los alrededores de Talavera de la Reina. Geomorfología Cuaternaria", en Cuaderna: Revista de estudios humanísticos de Talavera y su antigua tierra, n. 3 (1996), pp. 6 y ss.

2 Rodriguez, Antonio, y MORAleda, Alberto: “El Paleolítico en la zona de Talavera", en La Voz de Tajo, 17, 24 de febrero, 3, 10 y 17 de marzo de 1982; Diario Ya de Toledo, 17 de febrero de 1982 y 2 noviembre de 1983; La Región, 29 de septiembre de 1981. Vid. también EnAmorado, Josefina: "La ocupación humana del Pleistoceno en la comarca de Talavera", en Actas de las Primeras Jornadas de Arqueología de Talavera de la Reina y sus tierras, Toledo, 1992, pp. 39-55.

3 Desde época romana observamos un uso casi sagrado del agua expresado en las aras votivas a la ninfas, vinculadas a manantiales y fuentes curativas; por ejemplo, la inscripción de la Ninfas descubierta en el siglo XVII cerca de la villa de Saucedo, a unos $5 \mathrm{~km}$ al oeste de Talavera (vid. Fidel FITA: “Datos epigráficos e históricos de Talavera de la Reina”, Madrid, 1883, pp. 7-61. Sobre termas romanas en Talavera: PACHECO, César, y MORALEDA, Alberto: “Aportación al estudio de estructuras termales en Talavera de la Reina (Toledo)", en Actas del / Congreso Peninsular de Termalismo Antiguo. Madrid, UNED-Casa Velázquez, 1997, pp. 427-436. 


\section{LOS PUENTES DE TALAVERA}

Precisamente, la necesidad de doblegar ciertos elementos naturales y adecuarlos a las actividades humanas más perentorias origina la aparición de cierto tipo de creaciones artificiales en el medio. El caso de los puentes constituye un buen ejemplo del esfuerzo humano por salvar accidentes impuestos por la naturaleza y que obstaculizan la comunicación entre diferentes lugares. En este punto, está claro que la red hidrográfica condiciona bastante el trazado de itinerarios camineros y la ubicación de zonas de paso o franqueo de ríos o arroyos ${ }^{4}$.

La actividad pontonera en la zona de Talavera responde a una pauta seguida desde la época romana por solucionar el vadeo de importantes puntos en la red viaria. La dispersión de ésta por el área de la antigua Caesarobriga (Talavera de la Reina) ${ }^{5}$ se articula en torno a una gran vía que procedente de Emerita Augusta se dirigía por Toletum hasta Caesaraugusta, la conocida vía número 25 del Itinerario de Antonino ${ }^{6}$. A pesar de la omisión del topónimo Caesarobriga en dicho repertorio está demostrado que la ruta discurría al norte del Tajo pasando por Talavera, importante núcleo urbano durante el siglo III-IV d. C. La realidad caminera, sin embargo, no se queda en esta vía principal sino que se despliega una interesante red de caminos secundarios para comunicar la urbs con su territorio, sobre todo de cara al sur del Tajo. Por ello, el propio río se presentó desde los primeros momentos como un obstáculo serio para los ingenieros romanos, debido a la gran anchura de su cauce a su paso por Talavera.

4 CORdoBa de LA Llave, Ricardo: “La red hidrográfica y su incidencia sobre las comunicaciones por el término de Córdoba durante el siglo Xv", en Actas del // Congreso Internacional de Camineria Hispánica, Madrid, 1996, tomo II, pp. 211-234.

5 Rubio Fuentes, M. José: "Caesarobriga, ciudad romana de la Lusitania", en Actas del // Congreso Peninsular de Historia Antigua, 1990, Coimbra, 1993, pp. 567-580.

6 Fernández Miranda, M., y otros: “Alio Itinere ab Emerita Caesaraugusta: La vía romana entre Talavera de la Reina y Toledo y la implantación humana en el Valle Medio del rio Tajo", en Simposio La red viaria en la Hispania romana, Zaragoza, 1990, pp. 155-163. IDEM: “Indigenismo y romanización en la cuenca media del Tajo. Planteamiento de un programa de trabajo y primeros resultados", en Actas del Primer Congreso de Arqueología de la provincia de Toledo, Toledo, 1990, pp. 13-65. CoELLO, F.: "Vías romanas entre Toledo y Mérida", en Boletín de la Real Academia de la Historia, XV (1889), pp. 5 y ss. CABALLERo ZOREDA, Luis: “Las vías romanas entre Talavera y Toledo. Yacimientos romanos, sus influjos en la defensa musulmana durante la Reconquista", en La Iglesia y e/ Monasterio visigodo de Santa María de Melque (Toledo), San Pedro de la Mata (Toledo) y Santa Comba de Bande (Orense) en E.A.E., 109, Madrid, 1980, pp. 11 y ss. PACHECO, C., y MoRALEDA, A.: "Contribución al estudio de la red viaria en la zona de Talavera: El miliario de la Portiña", en Cuaderna, n.2 1 (1994), pp. 12-17. Álvarez, Yolanda: «Aportación documental para el estudio del trazado de la vía romana entre Talavera de la Reina y Toledo", en Actas de las Primeras Jornadas de Arqueología de Talavera y sus tierras, Toledo, 1992, pp. 159-176. 


\subsection{El Puente Viejo sobre el Tajo}

La solución aportada por la ingeniería romana para el primitivo puente sobre el Tajo en Talavera pasaba por fijar, lo más firmemente posible, la cimentación de las pilas y la articulación de un sistema de tajamares triangulares que de una forma efectiva contrarrestaran los empujes de las corrientes. Del examen detallado de los restos del puente romano se deduce que la tipología adaptada toma modelos genéricos de puentes imperiales con pilas y tajamares «aquillados", una buena obra de opus caementicium al interior de las mismas, y un forrado de sillares de muy buena factura, opus quadratum, y en ocasiones, de grandes dimensiones ${ }^{7}$. Ahora bien, el factor de perdurabilidad que la obra romana pudo tener en cuenta se vio descompensado por la increíble violencia de las aguas del Tajo que debieron de incidir en su paulatino desajuste y derrumbe.

La obra medieval del puente viejo sobre el Tajo en Talavera aprovecha algunas de las pilas romanas del antiguo puente. Esta reutilización, nota constante en la arquitectura pública talaverana durante el medievo, se aprecia no sólo estructuralmente sino en los mismos elementos que componen las pilas del puente medieval: uso de sillares con inscripciones epigráficas, por ejemplo ${ }^{8}$. El nivel de arrasamiento de la obra romana es patente; por el análisis arqueológico de las pilas del primitivo puente, que se encuentra por debajo de la cimentación de las pilas medievales, se observa que apenas se conservan dos hiladas del paramento de sillería romano, indistintamente consolidado (vid. fig. 2).

\subsubsection{Análisis histórico-documental}

Es bastante asombrosa la escasez de noticias documentales sobre este puente. Las fuentes medievales que hablan de Talavera, tanto en época islámica como después de la ocupación cristiana, hacen caso omiso de referencias al puente sobre el río Tajo ${ }^{9}$. La más antigua, el texto de lbn Hawqal, de mediados del siglo $x$, menciona sus tiendas, bazares, baños, mezquitas, etc. pero nada recoge acerca del primitivo puente. Lo mismo

7 Moraleda, Alberto, y PACHEco, César: El puente romano de Talavera de la Reina, Talavera, 1991, pp. 44-48.

8 En la cara norte del espolón de la segunda pila hoy visible desde la orilla de Talavera, se aprecia una de esta inscripciones funerarias, tan comunes en las murallas islámicas de la ciudad. Del intento de lectura de ésta tan sólo hemos podido reconstruir las siguientes letras hasta el momento, en espera de un estudio más detenido de esta inscripción: ROXV--/S.T.T.?

9 Vid. MARTínez Lillo, Sergio: “Talavera de la Reina en las fuentes medievales", en Cuaderna, ก. 4 (1996), pp. 66-91. 
ocurre con la Crónica del Moro Rasis donde se repite la ausencia de datos al respecto.

Un elemento, sin embargo, más ilustrador de las obras hidráulicas de la ciudad en el pleno medievo, es mencionado por Ibn Qattán hacia 1109. Se refiere a una presa que utilizaban los cristianos para conseguir que el agua del Tajo "lamiese» los muros de la fortaleza en el sector meridional del primer recinto fortificado ${ }^{10}$. Si este complicado sistema de inundación lo situamos en la zona del puente viejo puede argumentarse una posible correlación entre el primitivo puente romano, reformado casi con toda seguridad por los musulmanes, y la presa aludida por Qattán.

El problema, no obstante, se plantea por la falta de alusiones directas al puente en estos siglos centrales del medievo. Optaremos por otras vías de interpretación para intentar perfilar soluciones. La relación entre puente y fortificación de la ciudad está patente desde su misma concepción. El primer recinto amurallado, correspondiente con la medina musulmana, que aprovechó parte del trazado tardorromano, se levanta según Martínez Lillo entre mediados del siglo ix y una posterior reforma, en tiempo de Abd alRahman III (año 936/937) 11. La documentación bajomedieval registra la existencia de una de la puertas importantes de acceso a la villa en el sector meridional, la Puerta del Río ${ }^{12}$, que sin lugar a dudas existía ya en época romana, y que comunicaba el puente sobre el rio con la ciudad.

Esta correlación es lógica desde el punto de vista geoestratégico. EI agua suponía de por si un excelente medio de defensa para la misma ciudad, en tanto que esa mencionada presa no sólo es un medio de obtener agua para la irrigación mediante norias, o la inundación de parte del foso, que existía en el perímetro circundante de la muralla, sino un modo que tenía la propia villa de ofrecer resistencia si se efectuaba un ataque por el sur ${ }^{13}$.

Lo cierto es que la comunicación directa de la villa con el río se hace a través de la Puerta del Río y de otro postigo, llamado de Nazar, situado junto a una coracha, para el aprovisionamiento de agua en épocas de sitio. El puente toma pues, un papel relevante que por fuerza exigía una atención

10 Ibidem, p. 69.

11 MARTÍNEZ LILLO, Sergio: Arquitectura militar andalusi en la Marca Media. El caso de Talabira, Talavera, Excmo. Ayuntamiento, 1998.

12 Esta denominación es ya del siglo XV. En la documentación mozárabe del siglo xill se recoge la existencia de una Puerta de los Carros, "Bab al-marakib", que nosotros hemos identificado con esta misma puerta. PACHECO, César: Las antiguas puertas de Talavera de la Reina: estudio históricoarqueológico, Talavera, Excmo. Ayuntamiento, 2000.

13 Esta cuestión de la defensa de la villa es tratada por MARTínez LILlo, Sergio: en su artículo "Un ribat interior en la Marca Media. El caso de Talabira", en Cuadernos de Prehistoria y Arqueología, Madrid, Universidad Autónoma, 1995. 
privilegiada en las obras públicas de la Talabira musulmana. La ausencia de referencias no conlleva necesariamente la pérdida de protagonismo como elemento urbano de primer orden. El hecho de tratarse de un punto de conexión importante en la Marca Media entre las tierras del califato cordobés y la orilla norte del Tajo, convierte al puente de Talavera en un paso de gran valor estratégico como lo era la propia ciudad y la red de fortificaciones que en la zona talaverana existía.

La información más antigua que hemos localizado acerca del puente medieval es de 1227. Cuando el rey Fernando III ordenó controlar el comercio en los puentes del Tajo menciona a Toledo, Alarilla y Zorita, sin incluir Talavera, probablemente por encontrarse su puente fuera de servicio. Su ruina pudo deberse a diferentes causas, entre ellas las violentas avenidas del caudal del Tajo, registradas en años anteriores ${ }^{14}$. Según señala Julio González ${ }^{15}$, los pobladores de Talavera y su alfoz, sobre todo los del lado meridional del río, sufrian las consecuencias de esta incomunicación y la falta de apoyo en épocas de inseguridad, ante la vecindad de la tierra musulmana, pues hasta 1233 no se produce la toma de Trujillo por tropas cristianas. Ante esta situación, y dada la anchura del río, que hacia casi imposible tener un acceso entre ambas vertientes, empezaron a reconstruir el puente; el trazado rectilíneo del antiguo puente romano, probablemente ya arruinado, se varía entonces. En lugar de seguir el recorrido por las pilas romanas, pasado el primer tercio del puente partiendo de la villa se practica un cambio de dirección, bastante acusado, que provoca el característico quiebro de su trazado, a manera de tajamar aguas arriba.

El caso es que la obra, por su excesivo coste, no pudo sufragarse con los recursos disponibles por lo que el concejo acudió al Papa Honorio III que, en el referido año de 1227, concedía 20 días de indulgencia a cuantos ayudasen con limosnas y subsidios para poder acabar la obra del puente ${ }^{16}$. Esta obra del siglo XIII puede corresponder con los restos que en la actualidad se localizan cerca de los antiguos molinos, convertidos hoy en una central hidroeléctrica, que luego analizaremos. La más abundante documentación sobre este puente data ya del siglo XV.

Este puente pudo quedar inconcluso, o, al menos, sufrió nuevos desperfectos, por cuanto ya en la primera mitad del siglo Xv acusaba su estado ruinoso. El concejo volvió a poner en marcha una campaña de reformas del puente que, por lo que se deduce, debió de durar varios años. Entre los

14 Los Anales Toledanos / y / recogen noticias de grandes avenidas en el Tajo en los años 1113 , $1168,1178,1181,1200$ y 1203. En Los Anales Toledanos / y II. Edición de Julio Porres Martin-CLETO, Toledo, Diputación Provincial, 1993, pp. 218-221.

15 GonzÁLEZ, Julio: Reinado y diplomas de Fernando III. Vol. l: Estudio, Córdoba, 1980, p. 551.

16 Mansilia, Demetrio: La documentación pontificia de Honorio III, Roma, 1966. Documento n. ${ }^{2} 622$. 
años 1423 y 1427, según Jiménez de Gregorio se efectúa otra restauración ${ }^{17}$. Hacia 1449 se había iniciado otra obra; el Honrado Concejo de la Mesta, uno de los más frecuentes usuarios del puente, así lo hacia notorio cuando llega a un acuerdo con la villa de Talavera, materializado en la famosa Concordia de $1449^{18}$. En esta se declara:

"Por quanto la dicha villa de Talavera tiene començada a hedificar una puente de cal e canto en el río Tajo zerca de la dicha villa de Talavera e la quieren adobar de pilares de paso de madera bien alta e ancha, con azitaras de manera que bien e libremente pudieran pasar por ella agora e de aquí adelante para siempre jamás los hermanos del dicho concejo de la Mesta ...fazer entrada para la dicha puente por la dicha villa e arrabal e arrabal della rompiendo los muros e tapiando como quede calle hancha por do bayan los dichos ganados...".

Este acuerdo, que sirvió de modelo para concordias similares que la Mesta propició con los concejos por donde atravesaban sus ganados, suponía además la contraprestación para el Honrado Concejo de tener que pagar en concepto de pontazgo, un derecho de dos cabezas por cada mil ovinos o caprinos que pasaran por los puentes de la villa ${ }^{19}$; una forma de establecer ciertas garantías para mantener en buen estado el puente, si bien como es obvio, no dio excesivos resultados.

Directamente relacionado con la guerra civil en el reinado de Juan II, el alzamiento de Pero Sarmiento contra el rey y su valido, Alvaro de Luna en Toledo, pone en guardia a la villa en 1450 que organiza un sistema defensivo en sus murallas ${ }^{20}$. La rivalidad entre el concejo de Toledo y el de Talavera provoca ciertas escaramuzas y ataques de los toledanos a la villa: "por allende del río vino gente de Toledo e quebró la puente..." Así encontramos referencias en el libro de acuerdos del ayuntamiento talaverano de 1450 a la acción destructora que llevaron a cabo los toledanos sobre el puente:

"Los dichos señores acordaron de faser en el arco postrero un torrejón con su puerta para que los veçinos de Toledo no les torneren a quebrar la puente...»21.

17 JiMÉNEZ de Gregorio, Fernando: "Geografía de Talavera de la Reina", en Talavera en el Tiempo. Primer ciclo de conferencias '92, Talavera, 1994, p. 43. Ignoramos cuál es la fuente de este dato.

18 Se conserva original y copia simple en el Archivo Municipal de Talavera, Mesta 1449-1570.

19 Para los aspectos relacionados con la Mesta y los puentes de Talavera vid. CALDERÓN, Carlos: "Los puentes en la Castilla Bajomedieval", en Cuadernos de Historia de España, n. 71 (1989), p. 107, y MOLENAT, Jean P.: "Les communications en Nouvelle Castille au xve siècle et au debut du xvie siècle", en Les communications dans la Peninsule Iberique au Moyen Age, Paris, 1981, p. 159 ,

20 SuÁrez Álvarez, M. $a$ Jesús: La Villa de Talavera y su Tierra en la Edad Media (1369-1504), Oviedo, 1982, pp. 45 y ss.

21 Archivo Municipal de Talavera, Libro de Actas 1450-1459. Sesión de 9 diciembre de 1450. fol. $40 \mathrm{r}$. 
Iguaimente, al año siguiente todavía se insiste en la necesidad de reparaciones que tenía el puente ${ }^{22}$, obras que continuaban en $1452^{23}$. Las llevadas a cabo en estos años debieron de limitarse a ciertos arcos del puente y a la fijación de pasarelas de madera.

El otro gran hito de la historia constructiva del puente se sitúa bajo la prelatura del cardenal de Toledo, don Pedro González de Mendoza, verdadero artífice de obras públicas y amante de las artes ${ }^{24}$. La relación del prelado con la villa parece fue, por lo menos, asidua y en cierta manera beneficiosa en cuanto que dejó en su término algunas representaciones de su labor edilicia. Entre ellas la reforma de una de las puertas de acceso al primer recinto amurallado, el Arco de San Pedro, así como una importante actuación en materia de puentes.

El cronista local Fray Andrés de Torrejón alude en su obra manuscrita de 1596 a la construcción del puente en tiempos de Mendoza:

"Fray Pedro de los Molinos tanvién fue procurador y grande artífice en traçar obras y edifiçios y por entenderlo tanto, siempre que se ofreçía alguna cosa destas al ayuntamiento pedian al prior le diese liçençia para salir a verlas y traçarlas y por horden suya se hiço la puente deste río que está junto a la villa por donde se pasa a la Xara, la qual esta ya muy arruynada por las muchas y grandes avenidas y la poca firmeça que ay en la tierra ques muy arenisca.... 25 .

Se atribuye pues a este fray Pedro de los Molinos, de la orden de San Jerónimo, y profeso en el monasterio de Santa Catalina de Talavera, la dirección de las obras de reconstrucción de la primera parte del puente viejo, y que hoy se mantiene en pie. El historiador local Ildefonso Fernández y Sánchez ya reparó en este aspecto cuando diferenciaba la obra de Mendoza de la otra más antigua 26.

La actuación del cardenal, como señor de la villa, se reflejó epigráficamente encima de uno de los arcos del puente, concretamente donde hace

22 En diciembre de 1451 se menciona el repartimiento que quería hacer el concejo para sufragar las obras: «Se ayuntaron en ayuntamiento para faser rrepartimiento (al) conçejo para alçar los pilares de la dicha puente por quanto cada ves que viene (?) de agua llevan los pasos della e fase grande costa a la dicha villa" "para haçer repartiçión de ciento cincuenta mil maravedís..." (A.M.T.", Libro de Acuerdos de 1451 , fols. 78 y 79 ).

23 A.M.T." Libro de 1452, sesión 21 de enero, fol. 82 r. Pago del concejo de dos mil maravedis de madera para la obra del puente.

24 Porte Fernández-Alfaro, Pedro la: “El ideal urbano del cardenal Mendoza y el Hospital de la Santa Cruz", en Anales Toledanos, XXXII (Toledo, 1996).

25 TORREJÓN, Fray Andrés DE: Libro de las Antigüedades de Talavera, su iglesia Colegial, monasterios, parroquias, genealogias y varones ilustres que ha tenido en armas, religión y letras, Talavera, 1596, Mss. de la Biblioteca Nacional, sig. 1498, s/f.

26 FERNÁNDEZ SÁNCHEZ, Ildefonso: Historia de la Muy Noble y Leal Ciudad de Talavera de la Rejna, Talavera, Imp. Rubalcaba, 1896, pp. 333-334. 
el quiebro. Este ha sido tradicionalmente conocido como Arco de las Armas, evidentemente por encontrarse allí un pequeño templete con el escudo cardenalicio ${ }^{27}$. Además, se menciona una inscripción alusiva a la obra de Mendoza; la transcripción que hizo Antonio Ponz en $1773^{28}$ es la siguiente:

\section{"PETRUS DE MENDOZA / CARDENALIS HISPANIAE ARCHIEP./ TOLETAN. A. MCCCC..."}

Por supuesto que la lectura de la fecha está incompleta, pues como dice el mismo Ponz, el letrero estaba bastante desgastado. Aunque algunos autores suponen la obra del primer año del pontificado de Mendoza, 1483, por nuestra parte, nos inclinamos más bien por fechas más tardías, cercanas a 1490.

No obstante la reforma cardenalicia los deterioros del puente siguieron produciéndose en años posteriores. Nuevas noticias de reparaciones de 1502 nos hablan de arreglos en "los pontones e obras quebradas de la puente nueva de la dicha villa"; en este caso el regimiento mandaba pregonar aquellos que deberían hacerse "segund questá fecho un pontón quebrado que agora se fiso e adobó por Morales, maestro de molinos de don Juan de Ribera...» 29.

La crónica de Garcia Fernández (1560), la más antigua de las historias locales de la época moderna, nos describe asi el puente:

"Sobre el río de Tajo tiene esta villa una puente de XXV arcos, al principio de la qual junto al muro, está una açeña de molinos buena, $y$ adelante, pasadas dos terçias partes de la puente, está otra casa e açeña de quatro ruedas. Es hedifiçio muy prouechoso; hizose a costa de los propios de la villa vale de renta en cada un año mil et quinientas fanegas de trigo" 30 .

\subsubsection{Análisis arqueológico de los restos medievales del puente}

La dificultad que presenta el estudio arqueológico de este puente se debe a la cantidad de reformas que ha experimentado, formando un mo-

27 Este debió de perderse ya en el siglo xIx. Una representanción de su ubicación la tenemos en la magnífica panorámica del puente y la villa realizada en 1567 por Wyngaerde. Vid. KAGAN, R. L.: Ciudades del Siglo de Oro. Las vistas españolas de Anton Van den Wyngaerde, Madrid, 1986, pp. 347-348.

28 PONZ, Antonio: Viage de España en que se da noticia de las cosas más apreciables y dignas de saberse que hay en ella, Madrid, 1793. Edición de Aguilar, Madrid, 1988, tomo VII, p. 379. Recogido por JIMÉNEZ DE GREgorio, Fernando: "Tres puentes sobre el Tajo en el medievo", en HISPANIA, vol. XIV (1954), pp. 163-226.

29 A.M.T. Libro de Acuerdos de 1502, sesión 28 de enero, fols. 54 v. y 56 v.

30 García Fernández: Historia de la villa de Talavera, Talavera, 1560. Mss. de la B. N. sig. 1.722, fol. $13 \mathrm{r}$. 
saico de diferentes tipos de obras. No en vano algún autor le ha denominado "puentes de los remiendos» ${ }^{31}$ (vid. fig. 1). Bajo nuestra óptica vamos a intentar analizar los restos exclusivamente medievales, es decir, las edificaciones y reconstrucciones que se enmarcan entre el plenomedievo y finales del siglo $x v$, banda cronológica en la que nos vamos a mover.

Una de las cuestiones preliminares que hay que apuntar es el número de arcos que tenía el puente medieval. La referencia más antigua a este asunto es la del viajero Jerónimo Münzer (1493) ${ }^{32}$, quien especifica que el puente tenía entonces veintidós arcos. Este número creo que se aproxima bastante al que debió de tener el puente bajomedieval teniendo en cuenta los arcos que se contabilizan de esa cronología. No obstante, el puente que vio Münzer fue el que se acababa de reformar, sobre todo por la parte más próxima a la villa. García Fernández especifica que eran 25; cabe la posibilidad de que hubiera incluido los arcos de aliviaderos que se localizan en los ojos que hay cerca de los molinos, próximos a la orilla sur; o bien que contabilizara los que en ese momento se encontraban franqueados por estructuras de madera, como puede verse en la panorámica de Wyngaerden. En este, salvando las licencias que pudo permitirse el artista a la hora de interpretar la realidad, se pueden contar hasta 16 arcos, a los que habría que añadir otros cuatro más al principio del puente, que no se ven, y que corresponden con la obra del tiempo de Mendoza.

El caso es que el número de ojos puede haber variado sensiblemente del que tenía la estructura medieval por varias razones. Entre ellas, puede constatarse que la mayor luz de algunos de los arcos medievales, sobre todo los de la obra del siglo XIII-XIV, al derrumbarse, fueron posteriormente reconstruidos ubicando dos arcos en donde al principio hubo solamente uno. Esto parece observarse en algunos puntos donde las pilas no parecen guardar relación con las antiguas pilas medievales.

Para nuestro estudio tomaremos la cifra de 30 ojos, con una longitud total del puente que alcanzan los $520 \mathrm{~m}$. y una anchura media de $4,6 \mathrm{~m}^{33}$. De acuerdo con el cuadro cronotipológico (vid. cuadro 1) abordaremos el estudic pormenorizado de las estructuras medievales, dejando aparte aquellos restos producto de reformas esporádicas posteriores.

31 Ballesteros Gallafdo, Ángel: Patrimonio artístico de una ciudad: Talavera de la Reina, Talavera, Excmo. Ayuntamiento, 1981, p. 49.

32 MüNZEF, Jerónimo: Viaje por España y Portugal (1494-1495), Madrid, Ediciones Polifemo, 1991, p. 245.

33 Datos tomados del trabajo de Pérez FuEntes, Raul: Estudio sobre el puente viejo (de Talavera de la Reina), Tesis de licenciatura inédita, $\mathrm{s} / \mathrm{l}$., s/f. 
Obras públicas en Talavera de la Reina: los puentes medievales. Aproximación...

Restos medievales del puente, siglos XIII-XIV y XV

La correspondencia entre la información que nos dan los documentos y la que se deriva del estudio arqueológico del puente resulta complicada. Las atribuciones a la obra de reparación de 1227 es prácticamente imposible. Nos centraremos en el sector más meridional del puente, junto a los antiguos molinos, para intentar aproximarnos a la tipología constructiva de estos siglos.

Estos constituyen los tramos más antiguos del puente medieval, como ya advirtió Malalana Ureña ${ }^{34}$, y por su factura responde a un tipo de obra de sillería, conformando un aparejo regular si bien en algunas hiladas se deja ver cierta improvisación. La labor de cantería es por lo general bastante buena, siendo ésta más esmerada en la bóveda de los arcos, tanto de los mayores, como de los aliviaderos. El sillarejo suele utilizarse en los tímpanos, dejando una juntas más abiertas e imperfectas.

El esquema básico seguido en esta parte es similar al de otros puentes bajomedievales pero con ciertas particularidades: uso del arco apuntado antifunicular de varios centros ${ }^{35}$, que parte desde la misma base de la pila, y que permite la inexistencia del característico alomamiento de los puentes medievales. Los apoyos se resuelven con una ancha pila provista de tajamar y contrajamar triangulares y bastante prominentes, cuya altura no superaba la línea inferior del aliviadero. Por su misma anchura se opta por colocar encima una aliviadero de arco de medio punto, realizado con un dovelaje de buena silleria. En el interior de este se puede observar la presencia de dovelas rectangulares muy alargadas próximas a la línea de clave, y con un gran desgaste en las aristas. En las paredes de la bóveda y los muros se aprecia una tendencia al aparejo de sillería a soga, aunque de vez en cuando se coloca algún tizón (fig. n. ${ }^{\circ} 6$ ).

Este planteamiento puede observarse con claridad en el tramo de los ojos n. ${ }^{2} 24$ al 27 , donde en el siglo Xv o XVI se siguió el mismo criterio constructivo en la reforma del arco y aliviadero - arco 26-, pero esta vez con el uso del ladrillo como material (fig. ก.ํ 3). El tajamar triangular, bastante acentuado, permitía una mejor efecto de acción hidrodinámina en la base de la pila. Está realizado a base de buena sillería, de una altura media de $0,40 \mathrm{~m}$. de hilada, con algunos ripios en las juntas, y predomina el aparejo a soga, alternando con algún tizón, similar a lo que encontramos en las pare-

34 Malalana Ureña, Antonio: «Puentes-fortaleza en el Tajo: el tramo Zorita de los Canes (Guadalajara)-Castros (Cáceres)", en Boletín de Arqueología Medieval, n. 4 (1990), pp. 195-222.

35 Según la definición que aporta ARENAS DE PABLo, Juan J.: «Los puentes en la Baja Edad Media", en Tecnologia y sociedad: las grandes obras públicas en la Europa Medieval. Actas de la XXII Semana de Estudios Medievales de Estella (17-21 julio de 1995), Pamplona, 1996, pp. 111-152. 
des del aliviadero (fig. $n .{ }^{\circ} 5$ ). Por otra parte, estos tajamares engarzan sus hiladas con ias inferiores del arranque de la bóveda o salmer, del arco 27. Hay, no obstante, un detalle significativo por lo que puede aportar en el desarrollo evolutivo de la obra en esta parte; en el arranque de este arco de la pila norte, es decir, la posee el aliviadero o arco $n . .26$, se puede observar una primitiva hilada de sillería, formando salmer, sobre la cual al rectificar la nueva bóveda se cubrió la junta con aparejo de ladrillo en fechas posteriores, sin duda para proteger la obra del ataque directo de la corriente. Este elemento de arranque nos plantea la duda de si formaba parte de la obra del siglo XIII, cuyo plano fue posteriormente abandonado con la rectificación del inicio de la bóveda.

La rosca del arco n. 927 presenta una pronunciado pandeo debido a una desviación que en su momento se produjo de la calzada, especialmente visible en la cara este. Los tímpanos de este tramo poseen obra de sillería y sillarejos.

El esquema primitivo de arcos apuntados de dos centros con aliviadero encima de la pila comprendia todavía en el siglo XVI un tramo regular de tres pilas (vid. panorámica de Wyngaerde, fig. 15). El aliviadero más próximo a la orilla sur, el sucesivo al arco 27 , desapareció después del siglo XVI, quedando sólo su arranque, en la actualidad formando parte del arco n.. 28 (fig. n. ${ }^{\circ} 4$ ).

El otro arco similar, al menos tipológicamente, al 27 es el $n .{ }^{\circ} 17$, situado debajo de los antiguos molinos, hoy central hidroeléctrica. Aunque su luz es menor - 11,80 en el primero, y 9,00 $\mathrm{m}$ en el segundo-, pensamos que se puede relacionar con este primitivo puente.

La adscripción cronológica propuesta por Malalana para este tramo gira en torno a finales del siglo xIV y principios del $x{ }^{36}$, y en efecto parecen guardar muchos paralelos con los puentes al uso de esta época, con características muy comunes: el arco apuntado de dos centros, la colocación de arcos de aliviadero encima de las pilas, el diseño triangular tanto en el tajamar como en el contratajamar.

Ahora bien, el problema surge al intentar analizar el conjunto de la obra del siglo $x v$, presente en gran parte del puente, entre los arcos 0 y 16 y parte del resto. La diversidad de obras que hallamos, que pueden fecharse en este siglo y principios del siguiente, complica el análisis de los restos.

Teniendo en cuenta las noticias anteriormente comentadas, al menos habría que distinguir dos fases diferentes en las reformas del puente: una de las primeras décadas del siglo, que se prolonga en los años centrales

36 Malalana, op. cit., p. 202. 
del siglo con las reparaciones de los desperfectos de las acciones bélicas, y la que tradicionalmente se viene considerando obra del fraile jerónimo, por iniciativa del cardenal Mendoza.

En la primera fase podrian incluirse ciertas partes que más bien están complementando obras preexistentes y que en realidad viene a constituir una actuación de "urgencia" para mantener practicable el paso del puente, sobre todo por la necesidad de cara al paso de ganados de la Mesta. Aunque el proyecto comprendía la realización de una puente "de cal e canto", debió de limitarse tan sólo a algunas pilas; identificamos esta obra en determinadas pilas, en la actualidad casi desaparecidas o basculadas en su mayor parte. En estas la presencia del opus incertum es predominante en los aparejos de pilas y tajamares, con el uso de piedra amorfa de granito y fragmentos de ladrillos o canto de río.

El otro material, el ladrillo, se empieza a utilizar también en esta última fase medieval; en algún punto del puente lo observamos combinado con piedra: en el tímpano oeste, entre los n. ${ }^{\circ} 18$ y 19 se localiza un aparejo realizado a base de mampostería encintada, con restos de dos fajas, una de ellas de unos $34 \mathrm{~cm}$, entre verdugadas dobles de ladrillo. Se conectan directamente con las roscas de los arcos que están formadas por ladrillos de una modulación muy común $(30 \times 20 \times 4,5 \mathrm{~cm}$.). El esquema básico de mampostería encintada tiene muchas variantes, dentro de lo que se denomina "aparejo toledano", y su presencia se da obras tanto tardorromanas como alto y bajomedievales; en esta zona es exponente del mudejarismo de los siglos $\mathrm{XIV}_{\mathrm{O}} \mathrm{XV}^{37}$ (fig. $\mathrm{n} .{ }^{\circ} 7$ ).

\subsection{El Puente del río Alberche}

La importancia de este puente es vital desde el punto de vista de la aplicación de parámetros geohistóricos. El paso del río Alberche fue motivo de interés desde la antigüedad, dado que el trayecto este-oeste que se dispone perpendicular a este curso fluvial necesitaba de una solución caminera para salvar este obstáculo. En este sentido, en época romana, la ruta segui-

37 Acerca del problema de la mampostería encintada pueden verse los siguientes trabajos: MARTINEZ LILLO, Sergio: "La mamposteria encintada" capítulo de su libro Arquitectura militar andalusi en la Marca Media. El caso de Talabira, Talavera de la Reina, 1998, pp. 319-331. Pavón MaLdonado, Basilio: "Hacia un tratado de arquitectura de ladrillo árabe y mudéjar", en Actas III Simposio Internacional de Mudejarismo. Teruel, 1984, Teruel, 1986, pp. 329-364, y Dominguez PERELA, Enrique: «Materiales y técnicas en el arte mudéjar toledano: estructuras murales aparentes de la arquitectura religiosa", en Idem, pp. 491-505. Y ABAD CASTRO, M. Concepción: Arquitectura mudéjar religiosa en el arzobispado de Toledo, Toledo, 1991, vol. l, pp. 218-229. Miranda SÁnCHEZ, Antonio: Muros de Toledo, Toledo, 1994. 
da por la vía 25 del Itinerario de Antonino, el tramo desde Talavera hasta Toledo, por la parte septentrional del Tajo, cruzaría el río Alberche por un puente de cronología romana, que según algunos autores, se manifiesta en los restos actuales del puente ${ }^{38}$.

Este es uno de los aspectos más controvertidos acerca de este puente; la pregunta que nos surge es ¿hasta qué punto parte de los restos existentes se pueden considerar obra romana? Como suele ocurrir con otros ejemplos de la arquitectura pontonera resulta complicado asignar la romanidad a un puente que, en principio, puede adscribirse al medievo.

\subsubsection{Análisis histórico-documental}

Acerca de este puente son aun más escasas la referencias históricas. Aunque en documentación del siglo xll ya se menciona el río Alberich, o Alverch, el puente no se registra hasta el siglo XV.

Dentro de la comarca de El Horcajo, al este de Talavera, y constituyendo la puerta de entrada al entorno de la villa, este puente poseyó una privilegiada condición estratégica ${ }^{39}$. A través de él los ganados trashumantes de la Mesta que venía desde Escalona, se comunicaban por Talavera para pasar después por el puente del Tajo. Además era paso obligado para los viajeros y caminantes que procedentes de Toledo o de Madrid se dirigian hacia Extremadura, por el llamado Camino Real, ruta que tomaba en Talavera dos direcciones: una hacia Oropesa y tierras extremeñas y Portugal, y otro camino a Guadalupe pasando por la Villafranca del Puente del Arzobispo ${ }^{40}$, conocido según las fuentes por el "camino de los romeros que van a Nuestra Señora" 41.

Así pues, se desprende que en la Baja Edad Media la preocupación por el estado del puente fuera constante, pero no siempre compensaba el nivel impositivo de los pontazgos, que repercutían en las arcas municipales, con el óptimo aspecto de la obra. En 1438 los pecheros protestaban enérgicamente ante el arzobispo Juan de Cerezuela por el estado de semiabandono en que mantenía un puente que "ha rendido e rinde muchos maravedis en cada un

38 Fernández Miranda, Manuel, et al,: «Indigenismo y romanización en la cuenca media del Tajo. Planteamiento de un programa de trabajo y primeros resultados", en Actas del Primer Congreso de Arqueología de la provincia de Toledo, Toledo, 1990, pp. 18.

39 JIMÉNEZ DE GREgorio, Fernando: “La comarca de El Horcajo», Temas Toledanos, n. ${ }^{\circ} 76$, Toledo, 1993, pp. 31-32.

40 PACHECo JiméneZ, César: “Infraestructura viaria y hospedaje en Talavera, siglos XVI-XVI|», en Actas / Congreso de Camineria Hispánica, tomo /l "Caminería Histórica", Madrid, 1996, pp. 385-411.

41 SuÁREZ Álvarez, M. Jesús: "Las vías de comunicación en la zona de Talavera de la Reina en el período bajomedieval", en Actas de las Primeras Jornadas de Arqueología de Talavera de la Reina y sus tierras, Toledo, Diputación Provincial, 1992, pp. 201-214. 
Obras públicas en Talavera de la Reina: los puentes medievales. Aproximación...

año»; además el propósito era que el concejo se comprometiera a realizar una obra de más consistencia desde el punto de vista arquitectónico, pues aquel se negaba a hacer «hedificio alguno en ella (la puente) porque se faga la dicha puente toda de piedra e non aya madera, lo qual es pro común de todos" 42.

En la ya aludida Concordia entre la Mesta y el concejo talaverano de 1449 , también se estipulaba la obligación de la villa de mantener en buen estado y tener el puente «bien fecha e reparada con açicaras la su puente de Alverche» ${ }^{43}$. El acuerdo debió de surtir algún efecto pues en mayo de 1450 el ayuntamiento mandaba "adobar» 44 el puente, en una operación, suponemos, de parcheo mas que de proyecto estructural. El recurso de las vigas de madera fue el más utilizado, pues además de ser mucho menos costoso, solucionaba en menor tiempo el problema de la transitabilidad. Esta solución fue aplicada en multitud de puentes durante las reparaciones del bajo medievo, cuando se arruinaban o destruían los arcos de piedra o mampuesto, llegando a constituir incluso una tipología establecida en muchos puentes ${ }^{45}$.

El puente tuvo pues durante décadas pasarelas de madera para procurar su paso, una vez que la obra de arcos de fábrica -de sillería o de mampostería - se arruinó y se vino bajo en la parte de las bóvedas. Este aspecto es interesante para identificar cierto tipo de pilas que hemos localizado en los restos del mismo puente.

Aun así, viajeros y cronistas que hablan acerca de esta obra suelen señalar la presencia de piedra, referida fundamentalmente a las pilas. Por ejemplo, Andrés Navagero aseguraba que «cerca de Talavera pasamos por un puente de piedra un río que se llama el Alberca (Alberche) que podo después entra en el Tajo...» "46; o el viajero Claudio de Bronseval, que pocos años después raparó también en «un puente de piedra" al cruzar el mismo río ${ }^{47}$.

\subsubsection{Análisis arqueológico de los restos medievales del puente}

Para su estudio hemos asignado una numeración a cada pila y vano comenzando por el lado Este del río. En total se conservan 22 pilas, mas dos es-

42 Ibidem, p. 210. A.M.T., Ordenanzas, leg. 1, s/n.

43 Archivo Municipal de Talavera, Mesta 1449-1570. Concordia de 1449.

44 A.M.T. ${ }^{3}$ Libro de actas de 1450, sesión 6 de mayo, fol. 2 v.: «mandaron a Juan Ferrandes, regidor. que adobe la puente de Alverchen.

45 Vid. sobre el uso de la madera en reparaciones de puentes medievales CALDERón, Carlos: "Los puentes en la Castilla bajomedieval», en Cuadernos de Historia de España, n. 71 (1989), p. 69. Diaz MARTín, Luis Vicente: "La reparación de puentes a mediados del siglo xiv", en Castillos de España, n. 92 (1986), pp. 57-62.

46 NAVAGERO, Andrés: Viaje por España (1523-1524), Madrid, Turner, 1983, p. 30.

47 Bronseval, Claudio de: Viaje por España (1532-1533) (Peregrinatio Hispánica), Madrid, 1991. 
tribos en los extremos; el puente presenta en la actualidad un estado de ruina absoluta; tan sólo quedan en pie tres ojos del sector Este, $u$ orilla izquierdo del río: núms. 1 al 3 (fig. n.․․ 8). El resto de pilas están mayoritariamente recrecidas con obras de distintas épocas, aunque se distinguen con cierta facilidad las partes medievales, de mampostería o sillería, y la obras de ladrillo, incluso la realizada en los años 1920 cuando se hizo la última gran reforma del puente ${ }^{48}$.

Distinguimos diferentes tipologías de obras dentro de la etapa medieval del puente, que parecen identificarse con formas distintas de solucionar arquitectónicamente los arcos, las pilas y sus paramentos.

1) Tipo A de sillería: en una de las pilas centrales del puente -pila 9 encontramos en su planta doble tajamar triangular o aquillado. El paramento de éstos tiene esquinales de sillería y una tendencia a las hiladas de sillares, algunos peor trabajados, recibidos con ripios en las juntas (figs. $n .99$ y 10 ).

Nota importante es que la obra del tajamar se sobrepone al dovelaje de la bóveda del arco (fig. $n$. - 11). En esa misma pila, el arranque de la bóveda está realizado a base de buena sillería, bien escuadrada, si bien se deja ver el mortero a través de las juntas en algunas partes. Las hiladas suelen tener una altura en torno a 0,40 m., y mayoritariamente los sillares se disponen a soga, y muy escasos tizones; algunos poseen el característico hoyuelo para las pinzas elevadoras. Las hiladas superiores de lo que se conservan de la bóveda se encuentran un poco retranqueadas con respecto a las tres primeras (cara E de la pila 9).

$\mathrm{El}$ aparejo de esta pila ha sugerido a algunos investigadores la adscripción romana de este puente. En efecto, su volumetría y disposición parecen reproducir rasgos arquitectónicos romanos; sin embargo, por nuestra parte seguimos manifestando reservas a la hora de dar una cronología tan antigua a estos restos. Por otra parte, hemos encontrado muchos paralelos de este aparejo en otras obras de la arquitectura defensiva islámica de la misma ciudad de Talavera: uso de grandes sillares cuadrangulares, ripios insertados en las juntas, y la colocación de un sillar a tizón entre varios a soga, o el retranqueo de las hiladas superiores ${ }^{49}$ (vid. fig. n. ${ }^{\circ} 9$ ).

48 Llevada a cabo por la Jefatura de Obras Públicas de Toledo. Vid. Toledo: Revista de Arte, $n .8239$ (enero, 1927), s/p. Después de la Guerra Civil, y ante el deterioro que sufría el puente y las condiciones desfavorables para el tránsito de la carretera de primer orden Madrid-Extremadura, se construyó en los años 1950 otro nuevo puente, aguas arriba del puente viejo, actualmente en uso, siendo ministro de Obras Públicas el Conde de Vallellano (1951-1957). JIMÉnEZ DE GREGORIO, Fernando: «El puente viejo de Alberche”, en El Día de Toledo, 21 abril 1991.

49 Vid. MARtínez Lillo, Sergio: Arquitectura militar andalusi en la Marca Media: El caso de Talabira, Talavera, Excmo. Ayuntamiento, 1998. También PACHECO, César, y MoraledA, Alberto: “Arqueología medieval en Talavera de la Reina II: La fortaleza de la Puerta de Mérida", en Homenaje de Talavera y sus tierras a don Fernando Jiménez de Gregorio, Talavera, Excmo. Ayuntamiento, 1998, pp. 151-172. 
La tipología de sillería en las bóvedas y bases de pilas se encuentra en otras partes del puente: pilas $1,2,3,4,5,6,9,17,18$ y 19 . Ahora bien, creemos interesante distinguir al menos dos épocas diferentes en el uso de la sillería en el puente. Una, ya descrita para la pila 9, en la que se emplea una modulación de sillares mayores, cuadrangulares y rectangulares, con una altura media que ronda los $40 \mathrm{~cm}$. El ancho de la bóveda de sillares oscila entre 3,65 m. y $4 \mathrm{~m}$. Parece corresponder a un tipo de obra que reutiliza materiales, probablemente de origen romano, y los adapta a nuevos aparejos, adecuándolos a las hiladas con ripiado, apreciándose la falta de uniformidad entre ellas. Este tipo de obra, en principio, pensamos que puede situarse cronológicamente en torno al siglo $\mathrm{XI}$, bien de autoría musulmana o realizada por manos cristianas que reproducen ciertas técnicas empleadas por alarifes islámicos, y que en cualquier caso pudieron aprovechar restos anteriores de un puente romano (fig. 13).

Distintas del anterior, las bóvedas de sillería que hallamos en las primeras pilas del puente, algunas formando parte de los arcos que se mantienen en pie, presentan una anchura menor, en torno a 3,50 m. y la altura de las hiladas es mucho menor, algunas de $20 \mathrm{~cm}$, utilizando mayoritariamente sillares rectangulares alargados y dispuestos a soga (fig. 12). Cabe señalar que sirviendo de apoyo a este paramento existen una cimentación bastante sólida que al exterior presenta un aparejo de mampostería irregular, aunque formando ciertas hiladas y esquinales de sillería escuadrada (pila 4, cara W). A veces se ícaliza algún mechinal en esta base que puede formar parte de las reconstrucciones posteriores.

Desgraciadamente no se conserva ninguna bóveda completa de esta tipología, sino que están completadas con reparaciones del siglo XVI o posteriores en ladrillo (fig. 12).

2) Tipo $B$ de mampostería:

Con predominio de obra de mampostería, documentada exclusivamente en los restos de pilas y paramentos tanto del interior de los ojos, como en tajamares y espolones. Se sigue normalmente una costumbre de situar en los esquinales sillería y el interior de los paramentos está realizado a base de mampuesto de diferentes tamaños. En algunas pilas se suele tender a colocar hiladas de piedra de tamaño grande y medio sin desbastar, guardando cierta regularidad en la disposición.

En otra parte, esta forma de proceder es más anárquica y se obtiene un opus incertum tan característico de las obras bajomedievales, con las rejuntas vistas del mortero y fraguando con la piedra, formando a veces un presunto revestimiento del muro.

Hay que advertir, no obstante, que las obras de mampostería están presente en toda las estructuras medievales del puente, incluso en aquellas pi- 
las donde se utiliza la sillería en los arranque de bóvedas, hay reformas, cronológicamente posteriores, en las que el tajamar suele presentar una solución arquitectónica de este tipo.

3) Otros elementos: al margen de esas constantes constructivas se pueden identificar en puntos diferentes de la obra medieval otros elementos que ayudan a una aproximación cronotipológica del puente. En el tímpano sur del arco $n . .2$ se localiza un aparejo realizado a base de mampostería encintada, fórmula que no se aprecia en ningún otro sector del puente. El esquema básico de verdugadas de ladrillo, una o dos hiladas, y el mampuesto colocado entre ellas corresponde a una de las múltiples variantes del aparejo toledano que ya mencionamos más arriba, signo del mudejarismo de la zona del siglo XIV o XV.

Del estudio de estos restos se desprende que al menos encontramos dos fases diferentes de construcción (o reconstrucción) del puente en el medievo.

Primera FASE: aprovechando restos posiblemente de un puente romano, se levanta un puente de sólida sillería en bóvedas y pilas, con base de cimentación más irregular de mampostería, formando un hormigonado tanto en el núcleo de la pila como en el de la bóveda. Por la tipología constructiva podemos situarlo entre los siglos $\mathrm{X}-\mathrm{xl}$.

SEGUNDA FASE: Se efectúa una reforma del puente en la que las bóvedas de sillería de modulaciones mayores se sustituye por hiladas más bajas, de sillares alargados puestos a soga; de esta fase quedan restos repartidos de arranques de bóvedas, que nos sitúan en un momento probablemente del siglo XIV-XV.

TERCERA FASE: sin duda de mediados $y$ finales del siglo $X V$, tenemos un puente donde el paso de tablas era característico, según las propias fuentes documentales. Algunas pilas se recrecen hasta la altura de la rasante de la calzada, siendo inexistentes cualquier tipo de arranque de arcos ni bóvedas, lo que hace pensar en un tipo de puente de pilares de cal y canto, y pasarelas de madera.

CUARTA FASE: probablemente de los primeros años del siglo XVl; en esta se opta por fabricar arcos de ladrillo, de medio punto y rebajados, cuya anchura es sensiblemente menor a la que posteriormente alcanza con las reformas del siglo XVIII (fig. n.․ 12). En los tímpanos del arco se aplica un aparejo de mampostería encintada de tradición mudéjar.

\subsection{El puente del arroyo del Bárrago}

Este pontón, utilizando el término aplicado en el siglo XVI, carece de cualquier tipo de referencia documental, lo que dificulta su estudio como 
Obras públicas en Talavera de la Reina: los puentes medievales. Aproximación...

suele venir siendo habitual. El único elemento que nos acerca a su encuadre cronológico es una pieza heráldica que se extrajo del centro de su pretil hace varias décadas y que hoy se conserva en la "pared de los escudos" o muro de cabecera de la basílica de Nuestra Señora del Prado.

El escudo corresponde al cardenal don Juan Pardo Tavera, arzobispo toledano (1534-1545) y señor de la villa de Talavera. La duda que surge es si la fundación este puentecillo se debió a este prelado o a uno de sus predecesores. Por las trazas y aspecto constructivo nos inclinamos a pensar que la obra data de las últimas décadas del siglo $x v$ y puede estar en relación con la campaña de reformas y mejoras en la infraestructura urbana que realiza el ya mencionado cardenal Pedro González de Mendoza. La actuación de Tavera puede tratarse de alguna mejora posterior.

Se encuentra enclavado en el antiguo camino real a Guadalupe que en dirección sudoeste partía de Talavera y corriendo paralelo al río se dirigía al lugar de Calera y después a la Villafranca del Puente del Arzobispo; este camino se registra en las fuentes documentales pasando por el pago de Los Aflejes y próximo a la isla de Alariche en el río Tajo ${ }^{50}$.

El puente un alzado típico de lomo de asno, coincidiendo el vértice de la calzada con la rasante de la clave del arco central (fig. n. 14). El tablero alcanza una achura de $4,55 \mathrm{~m}$. incluyendo la de los pretiles, de $0,55 \mathrm{~m}$. cada uno. Consta de tres vanos con unas luces diferentes: el del este, $2 \mathrm{~m}$.; el central $4 \mathrm{~m}$. y el del extremo oeste 2,20. Parecen guardar una modulación equilibrada con una relación de 1:2 de los arcos laterales con respecto al principal. El aparejo de los tímpanos está realizado de mampostería de tamaño medio y un enripiado consistente, con llagueado provisto en ocasiones de trozos de tejas. El mortero es de una cal blanquecina muy compacta.

Las bóvedas de los arcos, de medio punto los tres, y las roscas son de sillería de granito, presentando sus caras exteriores y el intradós una buena factura y acabado, mientras que las caras interiores de las dovelas son más toscas. En arco central tiene como pieza de clave un estrecho sillar en forma de cuña por su lado meridional. Las hiladas del salmer y contrasalmer son de mayor altura que las superiores. En el paramento de la bóveda predomina la disposición a soga de los sillares.

En la base de los dos pilares, aguas arriba, se localizan restos de tajamares, muy destruidos que apenas permiten reconstruir su planta. En todo caso está claro que no superaban la altura del arranque de los arcos, nota distintiva de muchos puentes bajomedievales.

50 Suárez Alvarez, M." Jesús: “Las vías de comunicación...”, p. 204. A.M.T." Deslindes, leg. 2 , $\mathrm{s} / \mathrm{n}$ (1468) y Libro de Acuerdos de 1500-1501, fol. $12 \mathrm{v}^{2}$. 
A la altura de la rasante de la calzada se disponen dos verdugadas de ladrillos de $30 \times 20 \times 4 \mathrm{~cm}$. que marcan el inicio de los pretiles. Estos están realizados a base de un hormigonado de cal y canto de río, técnica muy usual en la arquitectura de los siglos XIV y XV de la zona, y tienen una altura media de unos $0,60 \mathrm{~m}$. En el vértice de la calzada y encima de la clave del arco central se levanta unos machones construidos de ladrillo a soga y tizón. El del pretil meridional está coronado con las losetas que cubren todo el paramento; pero el del norte presenta señales de arranque y actualmente tiene una altura de unos $0,90 \mathrm{~m}$; sobre él iría colocado el escudo heráldico del cardenal como símbolo del promotor de la obra.

La importancia de este puente como nexo de comunicación en una via tan principal en la Baja Edad Media es indiscutible; pero junto a este valor geoestratégico, destaca su aspecto práctico pues con esta obra se salvaba un paso peligroso en las épocas de mayores lluvias cuando solía desbordarse el arroyo del Bárrago. El cronista local Soto asegura que el cardenal Mendoza realizó varios de estos puentecillos en los accesos a la villa ${ }^{51}$, posiblemente algún otro el Camino Real a Extremadura, posteriormente reformados en el siglo XVIII 52 .

51 SoTO, Francisco DE: Historia de la antiquísima ciudad y colonia romana Elbora de la Carpetania, hoy Talavera de la Reyna, Talavera, 1722 (manuscrito transcrito en 1885 por Jiménez de la Llave), fol. 49 r. Soto aseguraba que el prelado Medonza "mandó hacer diversos puentes en algunos arroyos que pasan cerca de esta villa que hoy se conservan por ser de muy fuerte fábrica, y todos tienen sus armas".

52 En un puente del Camino de Extremadura sobre el arroyo Bárrago solía recibir el ayuntamiento a las personalidades y miembros de la Casa Real cuando pasaban por Talavera. Vid. FERNÁNDEZ y SÁnCHEZ, Ildefonso: Historia de la Muy Noble y Muy Leal Ciudad de Talavera de la Reina, Talavera, Imprenta Rubalcaba, 1896, p. 74. 


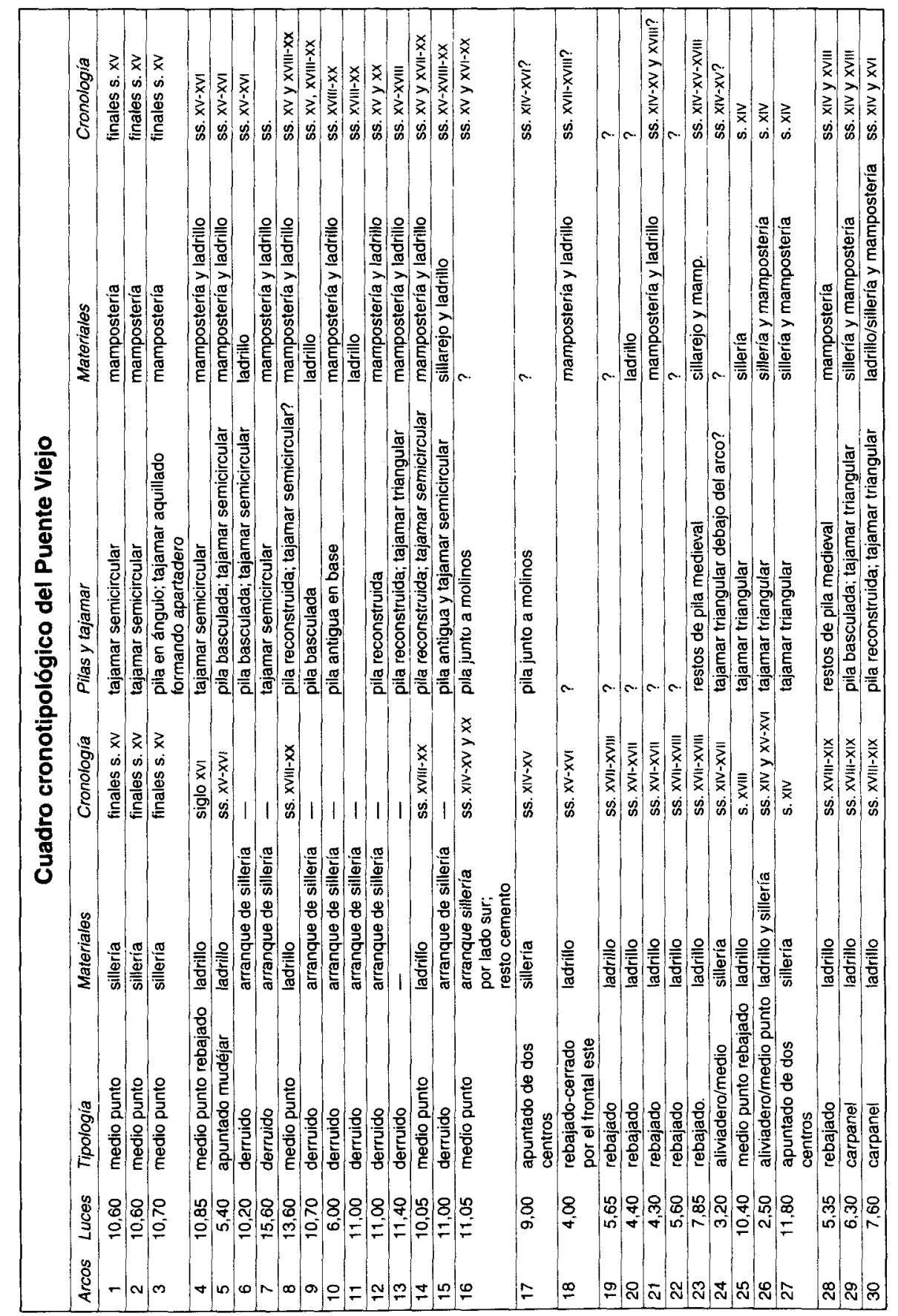




\section{BIBLIOGRAFIA}

ABad CaStro, M.a C.: Arquitectura mudéjar religiosa en el Arzobispado de Toledo, Toledo, Caja Castilla-La Mancha, 1991, 2 vols.

AL-IDRISI: Los caminos de Al-Andalus en el siglo XII, edición de Jassim Abid Mizal, Madrid, CSIC, 1989.

Alvarado, Segundo; Durán, Manuel; Nardiz, Carlos: Puentes históricos de Galicia, La Coruña, Colegio de Ingenieros de Caminos, 1990.

ANdRÉs MATEO, Carmen: Puentes históricos de la Comunidad de Madrid, Madrid, Comunidad, 1989.

Aramburu-Zabala, Miguel Ángel: La Arquitectura de puentes en Castilla y León, 1575-1650, Valladolid, Junta de Castilla y León, 1992.

ARENAS DE PABLo, J. José: "Los puentes en la Baja Edad Media", en Tecnología y sociedad: las grandes obras públicas en la Europa Medieval. Actas de la XXII Semana de Estudios Medievales de Estella (17-21 julio de 1995), Pamplona, Gobierno de Navarra, 1996, pp. 111-152.

CALDERón, Carlos: «Los puentes en la Castilla bajomedieval", en Cuadernos de Historia de España, n. 71 (1989), pp. 29-110.

CARRERo DE DIOS, Manuel: “Las murallas y las puertas de Toledo", Temas Toledanos, n.․ 14, Toledo, Diputación Provincial-I.P.I.E.T., 1981

CÓRDOBA DE LA LLAVE, Ricardo: "La red hidrográfica y su incidencia sobre las comunicaciones por el término de Córdoba durante el siglo XV», en Actas del II Congreso Internacional de Caminería Hispánica, Madrid, 1996, tomo II, pp. 211-234.

Díaz MARTín, Luis Vicente: “La reparación de puentes a mediados del siglo XIV», en Castillos de España, n.o 92 (1986), pp. 57-62.

FERnánDEZ Troyano, Leonado, et al.: “Esquema histórico de los puentes españoles", en La Obra pública: Patrimonio Cultural, Madrid, CEHOPU, 1986.

Fernández Miranda, M., y otros: «Alio Itinere ab Emerita Caesaraugusta: La vía romana entre Talavera de la Reina y Toledo y la implantación humana en el Valle Medio del río Tajo", en Simposio La red viaria en la Hispania romana, Zaragoza, 1990, pp. 155-163.

FERAÁNDEZ Y SÁNCHEZ, Ildefonso: Historia de la Muy Noble y Muy Leal Ciudad de Talavera de la Reina, Talavera, Imp. Rubalcaba, 1896.

GaRCia TAPIA, Nicolás: Técnica y poder en Castilla durante los siglos xvi y xvII, Salamanca, Junta de Castilla y León, 1989.

HERNÁNDEZ JIMENEZ, Félix: «El camino de Córdoba a Toledo en la época musulmana», en AlAndalus, 24 (1959).

- "Los caminos de Córdoba hacia el Noroeste en época musulmana", en Al-Andalus, 32 (1967), pp. 37-124 y 277-358.

JIMÉNEZ DE GREGORIO, Fernando: “Tres puentes sobre el Tajo en el medievo", en HISPANIA, vol. XIV (1954), pp. 163-226.

- "Geogratia de Talavera de la Reina", en Talavera en el Tiempo (Primer Ciclo de Conferencias '92), Talavera, Excmo. Ayuntamiento, 1994, pp. 27-50.

_- "El puente viejo de Alberche", en EI Día de Toledo, 21 de abril de 1991.

LIZ GuiRAL, Jesús: Puentes romanos en el Convento Jurídico Caesaraugustano, Zaragoza, Instituto Fernando el Católico-C.S.I.C., 1985.

Malalana UREÑa, Antonio: «Puentes-fortaleza en el Tajo: el tramo Zorita de los Canes (Guadalajara)-Castros (Cáceres)", en Boletín de Arqueología Medieval, n. 4 (1990), pp. 195-222. "Vías de comunicación terrestre en el reino de Toledo: el puente de Escalona (14791504)", en Anuario de Estudios Medievales, n. 18 (1988), pp. 575-589.

Martinez CARRILLO, M. ${ }^{2}$ de los Llanos: "Los puentes del Segura en la Murcia bajomedieval», en Actas del III Congreso Internacional de Caminería Hispánica, Guadalajara, 1997.

MARTINEZ LILLO, Sergio, y otros: "La continuidad de la red viaria de época antigua en época medieval en el Valle del Tiétar abulense", en Actas del /I Congreso Internacional de Caminería Hispánica, Madrid, 1996, tomo II, pp. 169-184.

- "Arquitectura militar islámica en Talavera de la Reina", en Actas de las Primeras Jornadas de Arqueología de Talavera de la Reina y sus tierras, Toledo, Diputación Provincial, 1992, pp. 177-200. 
- "Talavera de la Reina en las fuentes medievales", en Cuaderna: Revista de estudios humanísticos de Talavera y su antigua tierra, n.9 4 (Talavera, 1996), pp. 66-91.

MENÉnDEZ PIDAL, Gonzalo: Los caminos en la historia de España, Madrid, 1951.

- La España del siglo xiII leída en imágenes, Madrid, 1986.

Merino, María del Mar: "Castillos en el agua. Puentes medievales", en MOPU, Revista del Ministerio de Obras Públicas y Urbanismo, n. ${ }^{9} 347$ (1987), pp. 52-81.

Mesqui, Jean: "Grands chantiers de ponts et financements charitables au Moyen Âge en France", en Tecnología y sociedad: las grandes obras públicas en la Europa Medieval. Actas de la XXII Semana de Estudios Medievales de Estella (17-21 julio de 1995). Pamplona, Gobierno de Navarra, 1996, pp. 153-178.

MiRanda, Antonio: Muros de Toledo, Toledo, C.S.I.C.-Colegio de Arquitectos de Castilla-La Mancha, 1995.

Molenat, Jean Piérre: «En Espagne à la fin du xive siècle. La naissance de Puente del Arzobispo: une relecture", en Le Moyen Âge, t. LXXXVI (1980), pp. 234 y ss.

- "Chemins et ponts du nord de la Castilla au temps des Rois Catholiques", en Mélanges de Casa de Velázquez, VII (1971).

- "Les communications en Nouvelle Castille au xve siècle et debut du xvie siècle", en Les communications dans la Pèninsule Iberique au Moyen Age, Actes du Colloque tenu a Paules, 28 et 29 may 1980, Bordeaux, 1981.

MONTURIOL GONZÁlEZ, Ángeles: "Vias de comunicación y hacienda local en Madrid en el último tercio del siglo XV", en Caminos y caminantes por las tierras del Madrid Medieval, Madrid, 1994, pp. 141-164.

Moraleda Olivares, Alberto, y PACheco Jiménez, César: El puente romano de Talavera de la Reina, Talavera de la Reina, Excmo. Ayuntamiento, 1991.

Múnzer, Jerónimo: Viaje por España y Portugal, Madrid, Polifemo, 1991.

NAVAGERo, Andrés: Viaje por España (1524-1526), Madrid, Turner, 1983.

PACHECO JIMÉNEZ, César: “Infraestructura viaria y hospedaje en Talavera. Siglos XVI-XVII", en Actas del II Congreso Internacional de Caminería Hispánica, Madrid, 1996, t. II, pp. 385-411.

- "Los puentes medievales de Talavera de la Reina: una aproximación histórico-arqueológica», en Actas del IV Congreso Internacional de Caminería Hispánica, Madrid, 2000, t. I, pp. 373-398.

- Abastos y transportes entre Talavera y Madrid en el siglo xvil: El abastecimiento de carbón a la Corte, Talavera, Excmo. Ayuntamiento, 1993.

- «Almunias en la Talavera medieval: aproximación histórico-arqueológica al estudio del espacio rural islámico en el occidente de la taifa toledana", en Congreso Internacional: Entre el Califato y la Taifa: Mil años del Cristo de la Luz (Toledo, 14-16 diciembre 1999), Toledo, 2000, pp. 369-386.

- "Fortificaciones y vías de comunicación en la zona de Talavera en época romana y medieval», en V Congreso sobre Caminería Hispánica (julio-2000), en prensa.

PACHeco, César, y Moraleda, Alberto: "Contribución al estudio de la red viaria romana en la zona de Talavera", en Cuaderna, n. ${ }^{1}$ (Talavera, 1994), pp. 12-17.

PAvón MALDONADO, Basilio: Tratado de arquitectura Hispano-musulmana I: Agua, Madrid, C.S.I.C., 1990.

- Ciudades hispanomusulmanas, Madrid, Mapfre, 1992.

- "Arabismos y mudejarismos en la arquitectura toledana del arzobispo Don Pedro Tenorio", en Homenaje a Fernando Jiménez de Gregorio, Toledo, 1988, pp. 147-158.

Perez Fuentes, Raúl: Estudio sobre el puente viejo (de Talavera de la Reina), Tesis de licenciatura inédita, s/l., s/f.

PINO, J. Luis DEL, y ROJAS, Eva: “Infraestructura viaria y pontonera medieval en torno al Bembézar", en Estudios de Historia y Arqueología Medievales, XI (1996), pp. 365-415.

Rodriguez-Picavea Matilla, Enrique: La villa y la tierra de Talavera en la Plena Edad Media: Orígenes, consolidación y expansión de un concejo de realengo (siglos XI-xiII), Talavera, Excmo. Ayuntamiento, 1996.

RolG, Joan: «El puente como espacio público», en Arquitectura, n. ${ }^{9} 285$ (1990), pp. 112-117. 
Ruiz CaRmona, Samue!: Vias medievales en la provincia de Toledo. Análisis arqueologico e interpretación histórica, Tesis de licenciatura inédita, Universidad Complutense, Madrid, 1993.

- "Las cañadas de Talavera y su tierra en el siglo Xv". en Cuaderna (Revista de estudios humanisticos de Talavera y su antigua tierra). 1 (1994), pp. 18-31.

- "Propuesta metodológica para el estudio de las vías medievales II: Aplicación en la Sagra (Toledo)". en Actas del II Congreso Internacional de Camineria Hispánica, Madrid, 1996, tomo II, pp. 185-210

Sanchez Rey, J. Agustin: "El Puente del Arzobispo Tenorio cumple seiscientos años", en Revista de Obras Públicas, n. ${ }^{\circ} 3.220$ (diciembre, 1983), pp. 911-922.

Segura Graino. Cristina: "Problemas que plantea la investigación sobre caminos medievales", en Actas del II Congreso Internacional de Camineria Hispánica, Madrid, 1996. tomo II. pp. 273-278.

Suarez Alvarez, M a Jesús: "Las vias de comunicación en la zona de Talavera en el periodo bajomedieval», en Actas de las Primeras Jornadas de Arqueología de Talavera de la Reina y sus tierras, Toledo, Diputación Provincial, 1992, pp. 201-214.

- La Villa de Talavera de la Reina y su Tierra en la Edad Media (1369-1504). Oviedo, Universidad de Oviedo-Diputación Provincial de Toledo, 1982.

VEGA JIMENO, Miguel DE LA: "Puentes romanos y de origen romano en la provincia de Toledo", en Anales Toledanos, vol. XXXY (1994). pp. 17-40.

Vizuete Mendoza, José Carlos: Azutàn en el Antiguo Régimen, Cuenca, 1993.

ZozAYA Stabel-HANSEN, Juan "Notas sobre las comunicaciones en el al-Andalus omeya", en Actas II Congreso de Arqueologia Medieval Española, Madrid, 1987, pp. 220-228. 
Obras públicas en Talavera de la Reina: los puentes medievales. Aproximación...

\section{FIGURAS}

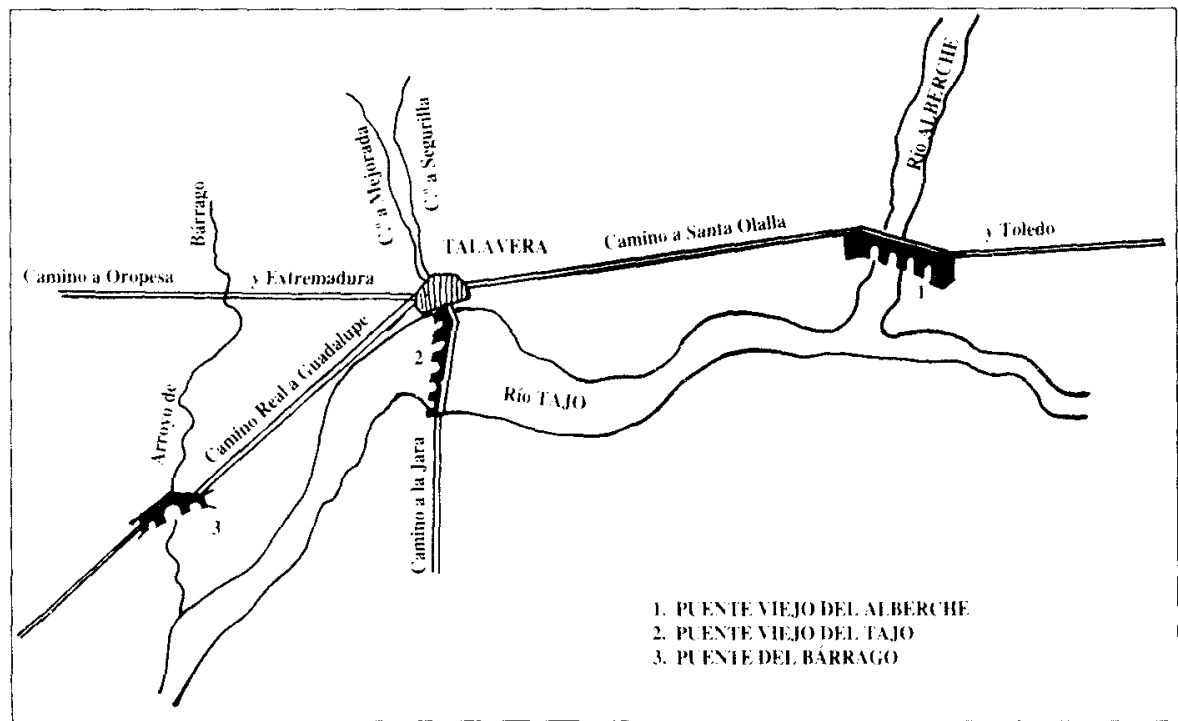

Plano: El entorno de Talavera en el siglo xv: Caminos y puentes principales. (Diseño: autor.)

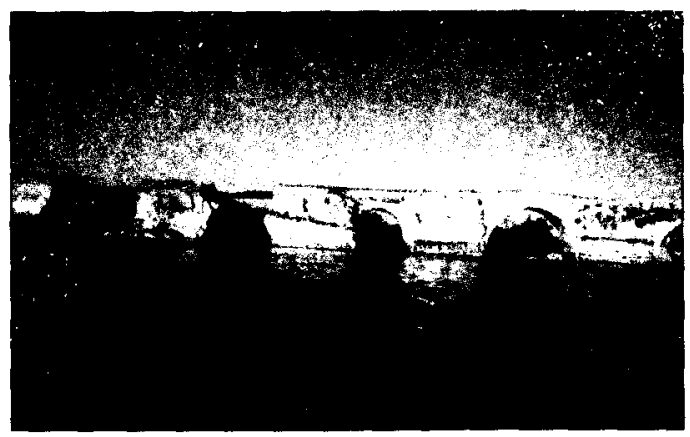

Figura 1: Vista general del Puente Viejo sobre el río Tajo. Talavera de la Reina. (Foto: C. Pacheco.)

Figuria 2: Puente Viejo: Detalle del aparejo de silleria romana bajo la obra medieval. (Foto: C. Pacheco.)

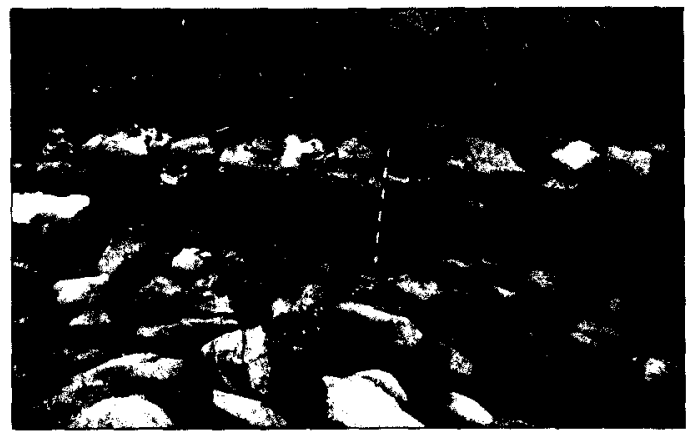




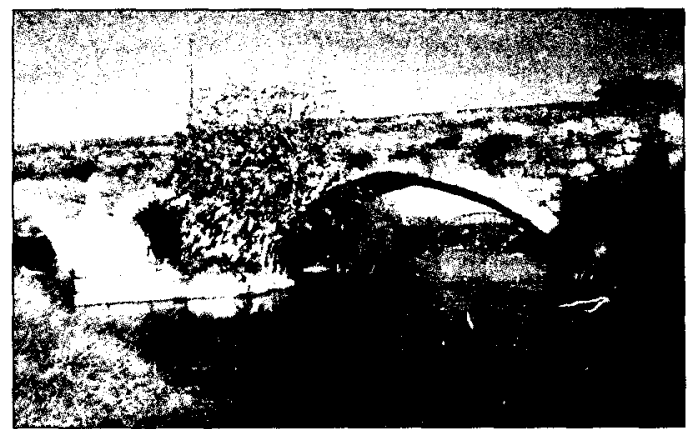

Figura 4: Puente Viejo: detalle de silleria junto al arco 27. (Foto: C Pacheco.)
Figura 3: Puente Viejo: arcos 26

(aliviadero) y 27. (Foto: C. Pacheco.)

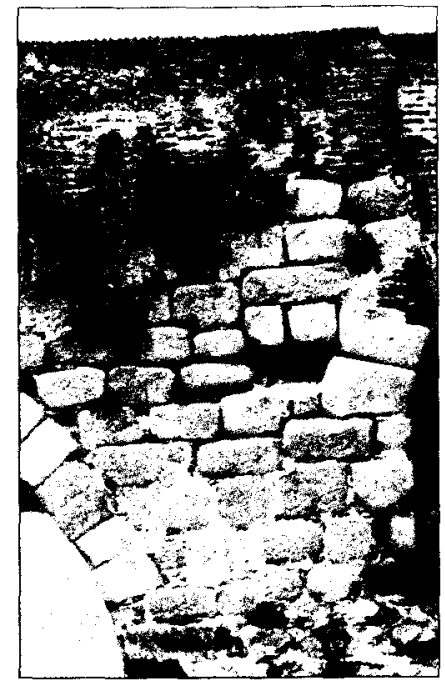

Figura 5: Puente Viejo: detalie del tajamar triangular entre el arco $25 y$ 27. (Foto: C. Pacheco.) 


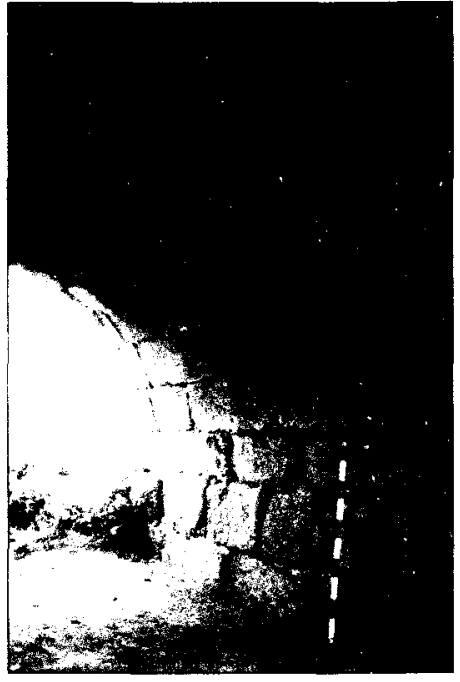

FiguRA 7: Puente Viejo: aparejo de mamposteria encintada mudéjar. (Foto: C. Pacheco.)
Figura 6: Puente Viejo: interior del aliviadero. (Foto: C. Pacheco.)

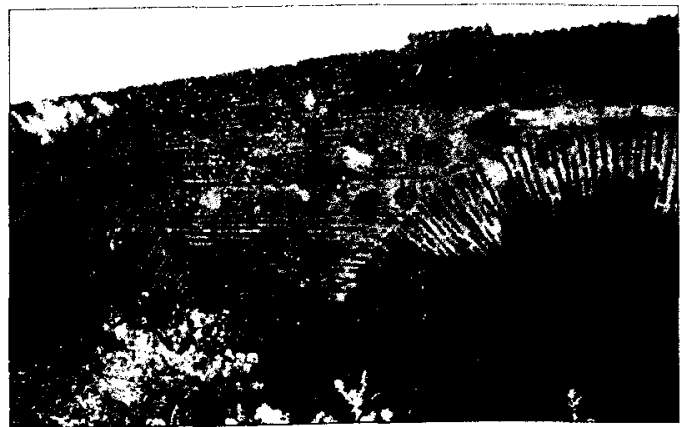

Figura 8: Vista general de los restos del puente viejo sobre el río Alberche. (Foto: C. Pacheco.)
Figura 9: Puente del Alberche: pila medieval y arranque de bóveda de silleria. (Foto: C. Pacheco:)

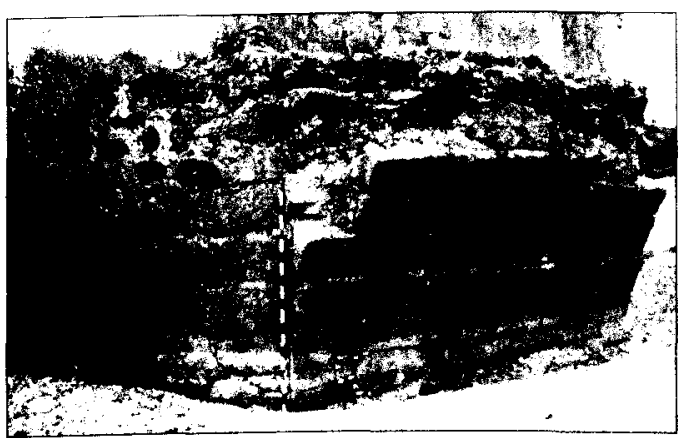




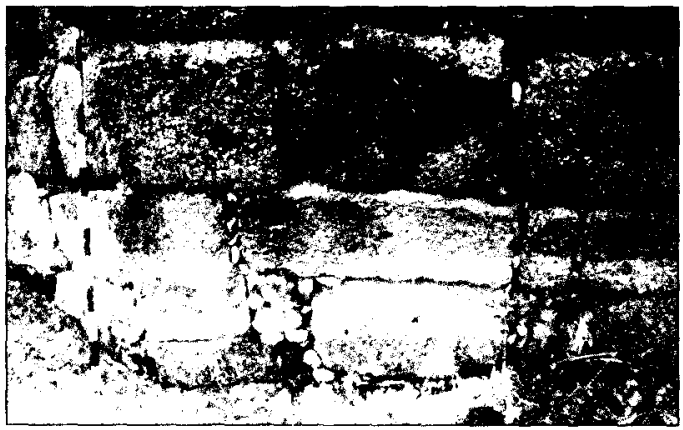

Figura 10: Puente del Alberche: sillares de posible origen romano. (Foto: C. Pacheco.)

Figura 11: Puente del Alberche: vista frontal del contratajamar triangular. (Foto: C. Pacheco.)
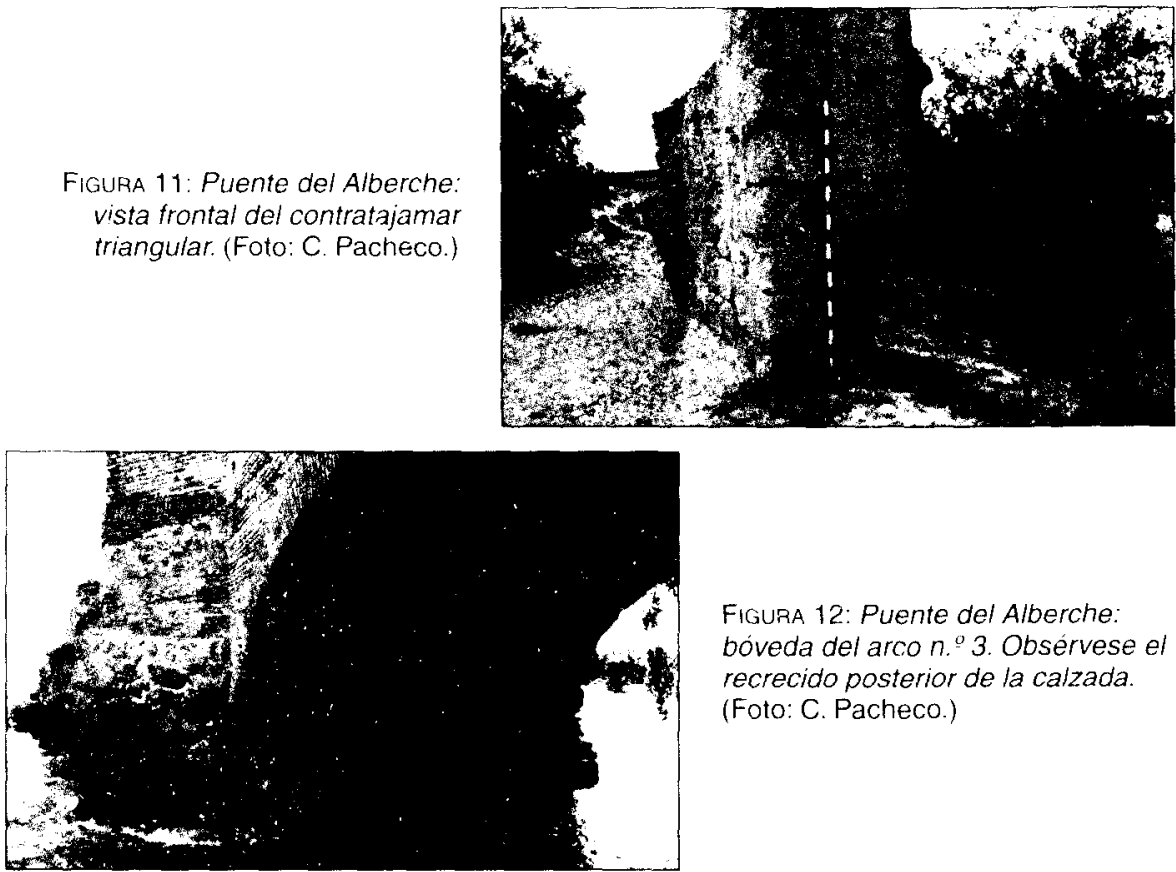

Figura 12: Puente del Alberche: bóveda del arco n. 3 . Obsérvese el recrecido posterior de la calzada. (Foto: C. Pacheco.)

Figura 13: Puente del Alberche: otra pila medieval y aparejo de silleria en la boveda. (Foto: C. Pacheco.)

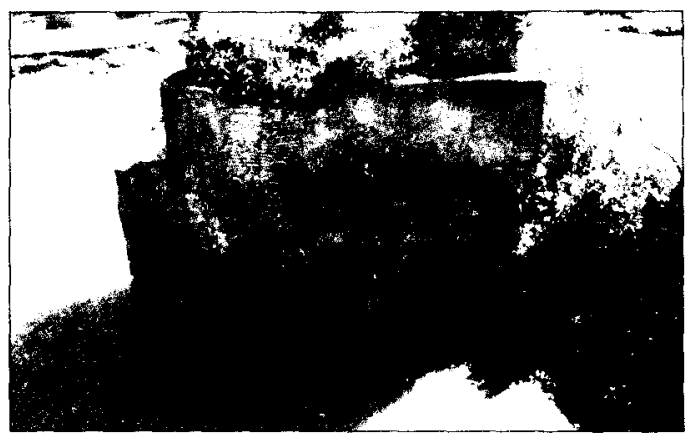




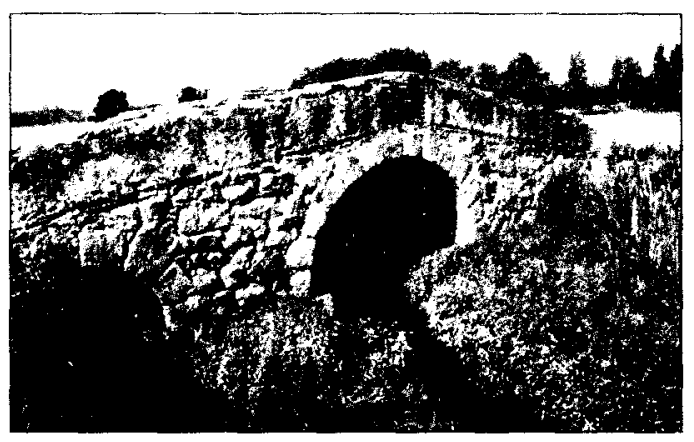

Figura 14: Cara sur del puente sobre el arroyo Bárrago (Talavera). (Foto: C.Pacheco.)
Figura 15: Detalle del puente medieval sobre el Tajo en al panoramica de Talavera de 1567 de Anton van den Wyngaerde. (Fuente: R. L. KAGAN, 1986.)

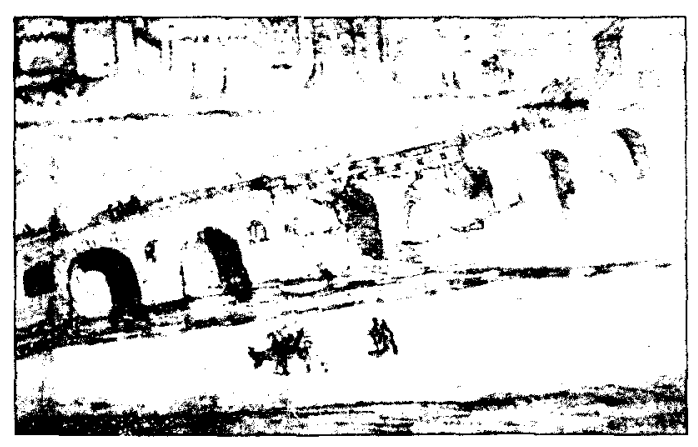

